\title{
EFEITO DA SALINIDADE SOBRE A SOBREVIVÊNCIA DAS LARVAS DE MACROBRACHIUM OLFERSII (WIEGMANN, 1836)
}

\author{
Molinari, A.J.J. ${ }^{1}$; Coelho, V.P. ${ }^{1}$; Pirovani, N.S.N. ${ }^{1}$ \& Preto, B.I. ${ }^{1}$ \\ ${ }^{1}$ Instituto Federal do Espírito Santo (IFES), Campus de Alegre/ES, Laboratório de carcinicultura e maricultura. \\ *Autor correspondente: annajuliajusti@gmail.com
}

\begin{abstract}
Objetivou-se avaliar o efeito da salinidade sobre a sobrevivência de larvas de Macrobrachium olfersii, cujo com nome popular pode ser conhecido como: Pitú, Potiporanga e na região em que foi realizado o trabalho é conhecido como Sapateiro. O trabalho foi realizado no Laboratório de Carcinicultura e Maricultura (Lacam) do Instituto Federal do Espírito Santo - Campus de Alegre. Fêmeas ovígeras de M. olfersii, com ovos em estágio inicial de desenvolvimento, foram alocadas individualmente em caixas de eclosão com água doce. Após a eclosão dos ovos, 200 larvas foram selecionadas aleatoriamente $0 ; 5 ; 10$ e 20 g de sal/L de água, totalizando 4 tratamentos e 50 repetições. As larvas foram mantidas em inanição. As unidades experimentais utilizadas foram tubos de ensaio, os tubos de ensaio foram preenchidos com $20 \mathrm{~mL}$ de água a cada uma das salinidades. Todas as unidades experimentais ficaram mantidas em "banho-maria", garantindo que a temperatura permanecesse em $28{ }^{\circ} \mathrm{C}$ diante todos os tratamentos. Diariamente foi renovado uma alíquota de $5 \mathrm{ml}$ para manutenção de aspectos importantes da qualidade da água. As larvas de $M$. olfersii foram avaliadas como vivas através da movimentação de seus apêndices. Houve diferença de sobrevivência dos animais submetidos à água doce em relação à sobrevivência dos submetidos aos demais tratamentos desde o primeiro dia de observação. Todos dos indivíduos submetidos à água doce morreram entre o primeiro e o segundo dia. Exceto o tratamento de $0 \mathrm{~g} \mathrm{Sal} / \mathrm{L}$, todos os outros obtiveram sobrevivência até o sétimo de observação. Os organismos expostos à salinidade de $5 \mathrm{~g} \mathrm{Sal} / \mathrm{L}$ obtiveram a maior sobrevivência até o quinto dia de avaliação, apresentando alta taxa de sobrevivência até o sexto dia, mas chegando ao final da avaliação com apenas uma larva. Os tratamentos que apresentaram uma taxa maior de sobrevivência e por mais tempo foram de 10 e $20 \mathrm{~g} \mathrm{Sal} / \mathrm{L}$, (três e quatro indivíduos respectivamente), onde houve morte total. Observou-se então que as larvas do M. olfersii necessitam de água salobra, sendo a de maior tolerância entre 10 e 20 g Sal/L.
\end{abstract}

Palavras-chave: Macrobrachium olfersii, salinidade, reprodução. 